\title{
Novel Hybrid Operating Table for Neurovascular Treatment
}

\author{
Jong-Hyun PARK, Jong Hyeon MUN, Dong-Seung SHIN, Bum-Tae KIM \\ Soonchunhyang University, College of Medicine, Bucheon Hospital, Department of Neurosurgery, Bucheon-Si, Gyeonggi-Do, Korea
}

Corresponding author: Bum-Tae KIM bumtkim@schmc.ac.kr

\section{ABSTRACT}

The integration of interventional and surgical techniques is requiring the development of a new working environment equipped for the needs of an interdisciplinary neurovascular team. However, conventional surgical and interventional tables have only limited ability to provide for these needs. We have developed a concept mobile hybrid operating table that provides the ability for such a team to conduct both endovascular and surgical procedures in a single session.

We developed methods that provide surgeons with angiography-guided surgery techniques for use in a conventional operating room environment. In order to design a convenient device ideal for practical use, we consulted with mechanical engineers. The mobile hybrid operating table consists of two modules: a floating tabletop and a mobile module. The basic principle of the mobile hybrid operating table is as follows: firstly, the length of the mobile hybrid operating table is longer than that of a conventional surgical table and yet shorter than a conventional interventional table. It was designed with the goal of exhaustively meeting the intensive requirements of both endovascular and surgical procedures. Its mobile module allows for the floating tabletop to be moved quickly and precisely. It is important that during a procedure, a patient can be moved without being repositioned, particularly with a catheter in situ. Secondly, a slim-profile headrest facilitates the mounting of a radiolucent head clamp system for cranial stabilization and fixation. Briefly, we have introduced a novel invention, a mobile hybrid operating table for use in an operating suite.

KEYWORDS: Operating table, Cerebral angiography, Operating room, Surgical fixation device

\section{INTRODUCTION}

$\mathrm{E}$ ver since Walter Dandy performed the first direct clipping of the neck of a cerebral aneurysm, the field of neurovascular treatment has been rapidly evolving (3). Advances in neurosurgical techniques made surgery the predominant mode of treatment until the last two decades. However, since Guglielmi detachable coils were approved by the US Food and Drug Administration in 1995, endovascular treatment has been established as an effective treatment method for neurovascular diseases. Furthermore, the endovascular management of such diseases is becoming more prevalent (1). However, one procedure cannot be said to be better than another without knowledge of the baseline characteristics that affect procedural outcomes. Current studies emphasize the usefulness of combining surgical and endovascular approaches, otherwise known as hybrid operations $(6,11,14)$. Traditional interventional tables have been found to be unsuitable for meeting the needs of such an operating unit and the associated operating environment. There is a need for interdisciplinary neurovascular teams to have access to a new working environment and hardware that integrates the needs for both interventional and surgical techniques.

We herein present a novel invention, a mobile hybrid operating table (mHOT) that provides the ability to conduct both endovascular and surgical procedures in a single session.

\section{MOBILE HYBRID OPERATING TABLE}

We provided surgeons with angiography-guided surgical techniques in the conventional operating room environment, and we designed a convenient and practical operating table to be used during the procedure.
Jong-Hyun PARK (1) : 0000-0003-2543-7375 Jong Hyeon MUN (1D) : 0000-0002-3380-9944
Dong-Seung SHIN (1) : 0000-0001-9326-4985

Bum-Tae KIM (D) : 0000-0003-2646-8165 
Conventional surgical tables have some limitations, such as being radiopaque owing to the metallic material of the tabletop and not being freely or intuitively adjustable during an operation. Likewise, conventional interventional tables also have limitations, such as the degree of difficulty with which the operating staff can be moved owing to the long length of the table. Additionally, there are difficulties in mounting special surgical equipment, especially the head clamp system for cranial stabilization and fixation.

Our table combines the benefits of interventional and surgical tables. Not only does it provide the radiolucency, mobility, and integration of imaging devices as found in conventional interventional tables, but also makes the proper accessories easily available, in that it includes rails for mounting surgical equipment clamps or retractors as found in a conventional surgical table. We worked with mechanical engineers to develop the idea for our device. We also obtained a patent from the Korean Government (patent number: 10-20140062487 obtained on 30/11/2015).

The mHOT consists of two modules: a floating tabletop and a mobile module (Figure 1A, B). More precisely, the mobile module is composed of the base unit and a firmly secure bracket.

\section{Floating Tabletop}

The tabletop consists of a material that offers $360^{\circ}$ radiolucency over long distances. The tabletop is designed for whole-body imaging, with a slim-profile headrest that permits the mounting of a radiolucent head clamp system. This extension supports the patient's body and allows for a radiolucent headrest to be attached to the end of the extension to support the patient's head during surgery. The long tabletop accommodates catheters and provides added space for placing sterile items in an easily-accessible location. It is designed with ample space to allow physicians, nurses, anesthesiologists, and technologists' access to the patient, making it easier for the team to work together effectively. Lateral fastening rails allow for the releasable fastening of equipment by means of a rail clamping device. In addition to the fastening rails already described, the tabletop itself is equipped with an additional set of guide rails onto which moveable modules can be slid. These, in turn, have their own set of fastening rails for securing rail clamping devices (Figure 2).

\section{Mobile Module}

The mobile module, which is comprised of the base part and a mobile bracket, attaches to the floor, while the floating tabletop rests on top of the base unit. The mobile bracket acts between the base unit and the floating tabletop in such a way that it is possible to move said bracket unit against the base unit and the floating tabletop. By means of the bracket, the floating tabletop can travel above the base unit. The floating tabletop can be adjusted for better access to the patient under examination. It can be moved horizontally in relation to the base unit. A bracket unit, acting between the base unit and the floating tabletop, can be moved with respect to the base unit and the floating tabletop. By means of this bracket unit, the support unit can travel beyond the base unit.
Restricted guidance is achieved by means of the rack gear, which is installed beneath the bracket unit and the groove. The bracket unit spans the distance between the end of the support unit and the guide apparatus of the base unit. Also, drive guidance is achieved with a spur gear which allows for the free-floating tabletop to be rotated with power-assisted motion, which facilitates panning. The spur gear shaft is connected to the drive motor, and the spur gear is either rotated or stopped according to the position of a switch provided on one side of the base.

There are two coupled under-floor table fixing frames which fix the mHOT to the floor, providing additional stability. Twin revolving wheels facilitate transportation. Also, a leveler allows for perfect stability and works as a brake.

\section{DISCUSSION}

Since Dandy introduced the combination of surgical and endovascular approaches in 1938, the hybrid approach has played an important role in the treatment of neurovascular disease (3). In particular, cerebral angiography is becoming ever more important because of its role in diagnosis, and cerebrovascular disease treatment strategies have been improving as well (15). In order to obtain better results during neurointerventional procedures, the development of novel techniques and equipment has become essential over the past 20 years (18).

Neuroendovascular procedures involving both diagnostic and therapeutic neurosurgery are increasing. While many endovascular procedures can be performed in conventional angiography suites, an environment with proper sterility and preparedness is needed to perform combined surgical exposure and endovascular procedures (2). In a conventional situation, if unforeseen technical complications occur, transferring the patient from the angiography suite to an operating suite may be necessary. This increases the risks of poor clinical outcomes in emergency situations.

Although Yamakawa et al. reported that the hybrid operation suite has no clearly defined potential added value for improving clinical outcomes (17), many other studies have anticipated the benefits of such an approach $(1,6,12,13)$. So, several studies have provided designs of hybrid operating rooms or units where both surgical and interventional procedures can be performed $(4,6,11)$.

Usually, a hybrid procedure room integrates elements of both surgery and interventional procedures. Such rooms can incorporate more sophisticated image guidance capabilities than do traditional surgical procedure rooms, and they can provide a greater degree of sterility control and anesthesia utilization than do traditional interventional rooms. Most of the studies conclude with an evaluation that states that improvement of the facilities, equipment, technologies, and processes is mandatory (5,9-12). However, there are several limitations that apply (12). First, the general size of a hybrid operating facility requires a relatively large operating space for the installation of equipment necessary for performing both open and closed procedures (7). Otherwise, the cost 

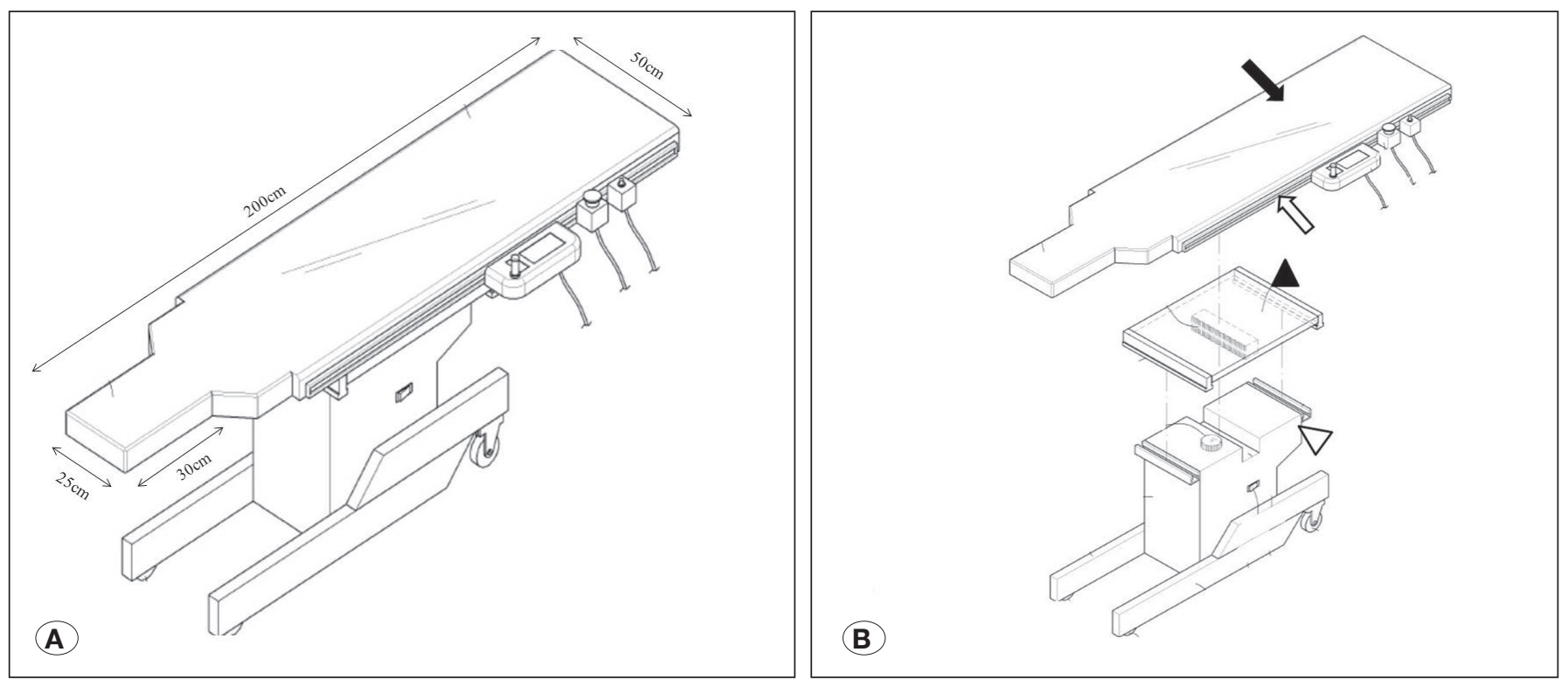

Figure 1: Illustrated image of the mobile hybrid operating table (mHOT). A) Perspective view of an operating table constructed according to the novel design scheme. The length and width are measured and described. B) The black arrow represents a radiolucent, floating tabletop with a slim-profile headrest. The white arrow represents lateral fastening rails. The mobile module consists of a base part (white arrowhead) and a mobile bracket (black arrowhead).

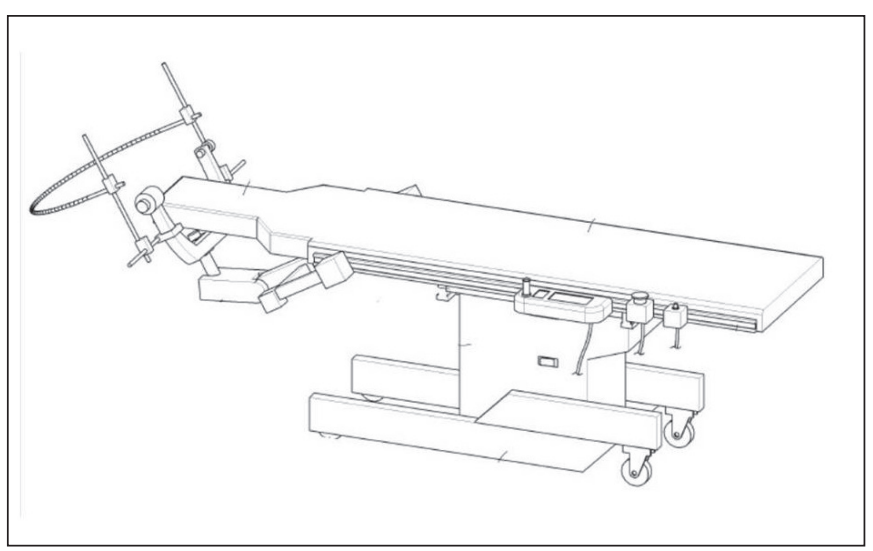

Figure 2: Illustrated image of the mHOT equipped with a radiolucent head clamp system mounting for cranial stabilization and fixation.

of room modification would be higher than it would be for conventional angiography suites and operating rooms. Second, current conventional interventional tables do not allow for the installment of proper accessories such as rails for the mounting of surgical equipment clamps or retractors, as do conventional surgical tables (16).

Therefore, we decided to develop a unique mHOT which provides not only the mobility associated with a conventional interventional table but also the availability of proper accessories associated with a general operating facility. We consulted with mechanical engineers during our creative process. The mHOT includes two modules, a floating tabletop and a mobile module. It is easy to use in practice. First, the $\mathrm{mHOT}$ is longer than a conventional surgical table but shorter than a conventional interventional table in a way which allows for the performance of both surgical and interventional requirements in a general operating facility. Second, the mobile module allows for fast and precise movements during surgery. Third, a slim-profile headrest makes it easy to mount a supporting radiolucent head clamp system for cranial stabilization and fixation (Figure 3A, B).

The mHOT that we developed has several advantages over commercially available hybrid tables (for example, MAQUET MAGNUS, Philips, Best, The Netherlands) in the operating field. Commercially available hybrid tables use floor-mounted systems that interrupt rapid panning over wide anatomic areas and limit the potential success of procedures (7). On the other hand, the mHOT provides for free installation, where the table is easily mounted to the floor and is readily moveable from room to room as required. Often, surgical/endovascular procedures will be performed in a room that does not make use of a particular table that is already in the room.

Secondly, as mentioned earlier, mHOT has a radiolucent, slimprofile headrest with an elongated, tapered edge that provides easier temporal and over-the-brow access to the head area and provides enough space on which to mount a head clamp system.

We performed a total of 66 cerebral angiography procedures and 95 neuroendovascular treatments using the $\mathrm{mHOT}$ at our institution. The mHOT has been applied in cases in which we anticipated encountering unexpected technical difficulties during the procedure, which would change an endovascular treatment to a surgical procedure, or in cases where a combined surgical and endovascular approach was necessary (8). As neuroendovascular treatments, we performed 55 

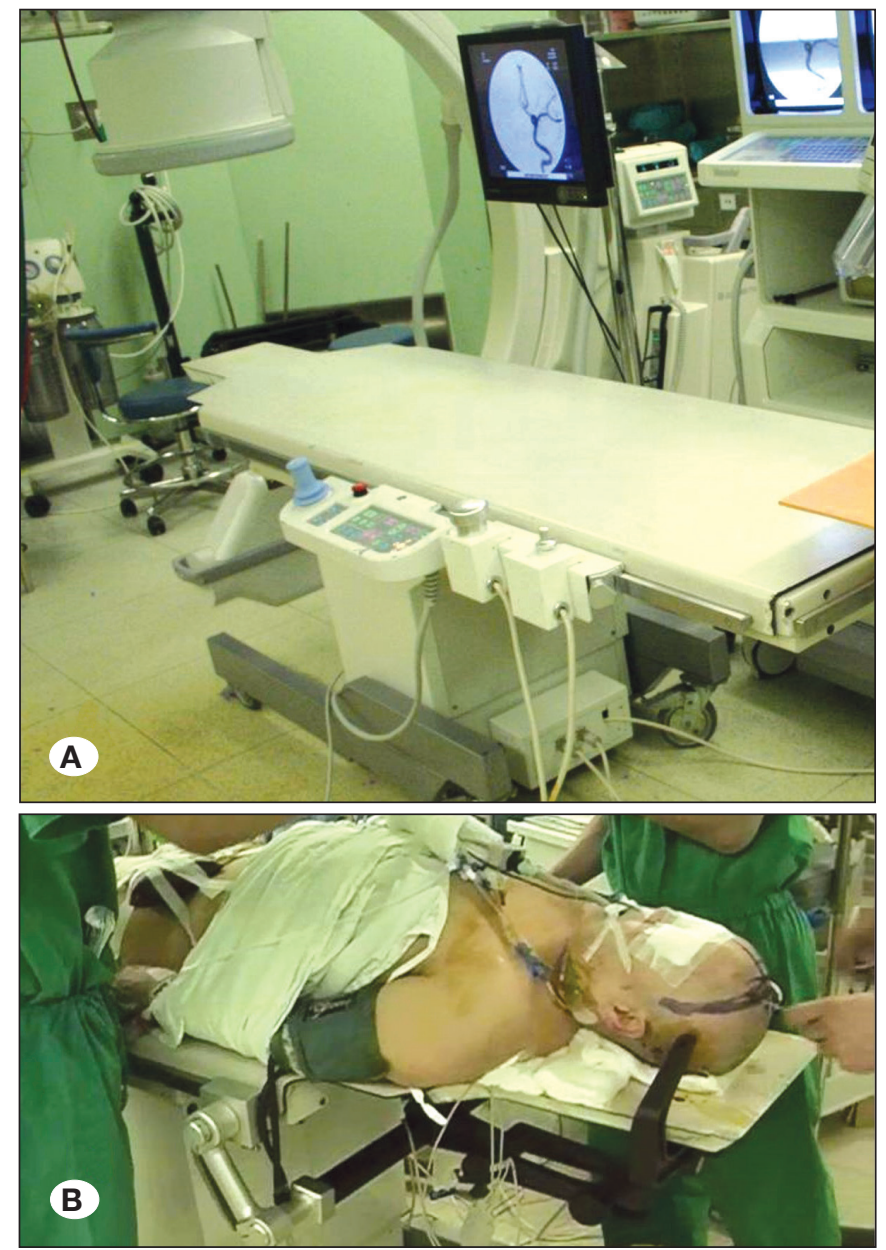

Figure 3: A) Photo of the $\mathrm{mHOT}$ in an operating room taken with a mobile digital subtraction angiography (DSA) system. B) Picture of the $\mathrm{mHOT}$ during a combined surgical/endovascular procedure.

aneurysm coil embolizations, 13 carotid stentings, 2 intracranial stentings, 10 intraarterial thrombectomies for acute infarct, 11 chemical angioplasties, 2 glue embolizations for arteriovenous malformations, and 2 meningioma embolizations.

The mHOT allows endovascular and surgical procedures to be done simultaneously in a single session. In brief, the integration of interventional and surgical suite technologies is a step towards improving outcomes during neurovascular surgery.

\section{CONCLUSION}

We have developed a mobile hybrid operating table for operating units. We believe that it offers several advantages over conventional interventional suites and surgical rooms.

\section{ACKNOWLEDGEMENT}

This work was supported by Soonchunhyang University Research Fund.

\section{REFERENCES}

1. Ahn SH, Prince EA, Dubel GJ: Basic neuroangiography: Review of technique and perioperative patient care. Semin Intervent Radiol 30(3): 225-233, 2013

2. Armonda RA, Thomas JE, Rosenwasser RH: The interventional neuroradiology suite as an operating room. Neurosurg Clin $\mathrm{N}$ Am 11(1): 1-20, vii, 2000

3. Dandy WE: Intracranial aneurysm of the internal carotid artery: Cured by operation. Ann Surg 107(5): 654-659, 1938

4. Etminan N, Brown RD Jr, Beseoglu K, Juvela S, Raymond J, Morita A, Torner JC, Derdeyn CP, Raabe A, Mocco J, Korja M, Abdulazim A, Amin-Hanjani S, Al-Shahi Salman R, Barrow DL, Bederson J, Bonafe A, Dumont AS, Fiorella DJ, Gruber A, Hankey GJ, Hasan DM, Hoh BL, Jabbour P, Kasuya H, Kelly ME, Kirkpatrick PJ, Knuckey N, Koivisto T, Krings T, Lawton MT, Marotta TR, Mayer SA, Mee E, Pereira VM, Molyneux A, Morgan MK, Mori K, Murayama Y, Nagahiro S, Nakayama N, Niemela M, Ogilvy CS, Pierot L, Rabinstein AA, Roos YB, Rinne J, Rosenwasser RH, Ronkainen A, Schaller K, Seifert V, Solomon RA, Spears J, Steiger HJ, Vergouwen MD, Wanke I, Wermer MJ, Wong GK, Wong JH, Zipfel GJ, Connolly ES Jr, Steinmetz H, Lanzino G, Pasqualin A, Rufenacht D, Vajkoczy P, McDougall C, Hanggi D, LeRoux P, Rinkel GJ, Macdonald $\mathrm{RL}$ : The unruptured intracranial aneurysm treatment score: $\mathrm{A}$ multidisciplinary consensus. Neurology 85(10): 881-889, 2015

5. Gross BA, Albuquerque FC, Moon K, Ducruet AF, McDougall CG: Endovascular treatment of previously clipped aneurysms: Continued evolution of hybrid neurosurgery. J Neurointerv Surg 9(2):169-172, 2017

6. Hacein-Bey L, Connolly ES Jr, Mayer SA, Young WL, PileSpellman J, Solomon RA: Complex intracranial aneurysms: Combined operative and endovascular approaches. Neurosurgery 43(6): 1304-1312; discussion 1312-1303, 1998

7. Hudorovic N, Rogan SA, Lovricevic I, Zovak M, Schmidt S: The vascular hybrid room-operating room of the future. Acta Clin Croat 49(3): 289-298, 2010

8. Kim SK, Shin DS, Kim BT: Neuroendovascular operating room: Setup, clinical application and future direction. J Korean Soc Intravasc Neurosurg 5: 32-37, 2010

9. Ludwig S, Hoffmann R, Grutzmann R: Hybrid operation for a thoracoabdominal aortic aneurysm. Zentralbl Chir 137(5): 414-416, 2012

10. Murayama $\mathrm{Y}$, Arakawa $\mathrm{H}$, Ishibashi $T$, Kawamura D, Ebara M, Irie K, Takao H, Ikeuchi S, Ogawa T, Kato M, Kajiwara I, Nishimura S, Abe T: Combined surgical and endovascular treatment of complex cerebrovascular diseases in the hybrid operating room. J Neurointerv Surg 5(5): 489-493, 2013

11. Murayama $\mathrm{Y}$, Irie $\mathrm{K}$, Saguchi $\mathrm{T}$, Ishibashi $\mathrm{T}$, Ebara $\mathrm{M}$, Nagashima $H$, Isoshima $A$, Arakawa $H$, Takao $H$, Ohashi H, Joki T, Kato M, Tani S, Ikeuchi S, Abe T: Robotic digital subtraction angiography systems within the hybrid operating room. Neurosurgery 68(5): 1427-1432; discussion 1433, 2011

12. Murayama Y, Saguchi T, Ishibashi T, Ebara M, Takao H, Irie K, Ikeuchi S, Onoue H, Ogawa T, Abe T: Endovascular operating suite: Future directions for treating neurovascular disease. $J$ Neurosurg 104(6): 925-930, 2006 
13. Schaller K, Cabrilo I, Pereira VM, Bijlenga P: Hybrid operation theatre from the perspective of neurosurgery. Chirurg 84(12): 1041-1047, 2013 (In German)

14. Shi ZS, Ziegler J, Duckwiler GR, Jahan R, Frazee J, Ausman $\mathrm{JI}$, Martin NA, Vinuela F: Management of giant middle cerebral artery aneurysms with incorporated branches: Partial endovascular coiling or combined extracranial-intracranial bypass-a team approach. Neurosurgery 65 Suppl 6: 121-129; discussion 129-131, 2009

15. Shin DS, Yeo DK, Hwang SC, Park SQ, Kim BT: Protocols and results of resident neurosurgeon's transfemoral catheter angiography training supervised by neuroendovascular specialists. J Korean Neurosurg Soc 54(2): 81-85, 2013
16. ten Cate G, Fosse E, Hol PK, Samset E, Bock RW, McKinsey JF, Pearce BJ, Lothert M: Integrating surgery and radiology in one suite: A multicenter study. J Vasc Surg 40(3): 494-499, 2004

17. Yamakawa K, Kiyama S, Murayama Y, Uezono S: Incidence and neurological outcomes of aneurysm rupture during interventional neuroradiology procedures in a hybrid operating suite. J Anesth 26(4): 592-594, 2012

18. Yilmaz A, Ozkul A, Shin DS, Im SB, Yoon SM, Kim BT: Morphological assessment of cadaveric radial, brachial and subclavian arteries: A neurointerventional approach. J Korean Neurosurg Soc 58(6): 499-503, 2015 